Delft University of Technology

\title{
Calculation of model parameters by EMG during dynamic motion of human arm
}

Gursel Ozmen, Nurhan; Van Der Helm, Frans C.T.; Schouten, Alfred C.

DOI

10.1109/BIYOMUT.2017.8479261

Publication date

2018

Document Version

Final published version

Published in

Proceedings of the 21st National Biomedical Engineering Meeting (BIYOMUT 2017)

\section{Citation (APA)}

Gursel Ozmen, N., Van Der Helm, F. C. T., \& Schouten, A. C. (2018). Calculation of model parameters by EMG during dynamic motion of human arm. In Proceedings of the 21 st National Biomedical Engineering Meeting (BIYOMUT 2017) [8479261] IEEE . https://doi.org/10.1109/BIYOMUT.2017.8479261

\section{Important note}

To cite this publication, please use the final published version (if applicable).

Please check the document version above.

\section{Copyright}

Other than for strictly personal use, it is not permitted to download, forward or distribute the text or part of it, without the consent of the author(s) and/or copyright holder(s), unless the work is under an open content license such as Creative Commons.

\section{Takedown policy}

Please contact us and provide details if you believe this document breaches copyrights.

We will remove access to the work immediately and investigate your claim. 
Green Open Access added to TU Delft Institutional Repository

'You share, we take care!' - Taverne project

https://www.openaccess.nl/en/you-share-we-take-care

Otherwise as indicated in the copyright section: the publisher is the copyright holder of this work and the author uses the Dutch legislation to make this work public. 


\title{
İnsan Kolunun Dinamik Hareketi Esnasında Model Parametrelerinin EMG ile Hesaplanması \\ Calculation of Model Parameters by EMG During Dynamic Motion of Human Arm
}

\author{
Nurhan Gürsel Özmen ${ }^{1}$, Frans C.T. van der Helm ${ }^{2,3}$, Alfred C. Schouten ${ }^{2,4}$ \\ 1. Makina Mühendisliği Bölümü, \\ Karadeniz Teknik Üniversitesi, 61080, Trabzon, Türkiye \\ \{gnurhan\}@ktu.edu.tr \\ 2. Department of Biomechanical Engineering, \\ Delft University of Technology, Mekelweg 4, 2628 CD Delft, The Netherlands \\ \{f.c.t.vanderhelm, a.c.schouten\}@ tudelft.nl
}

3. Department of Physical Therapy and Human Movement Sciences, Northwestern Univesity, Chicago, IL 60611, USA

4. Department of Biomechanical Engineering, University of Twente, PO Box 217, 7500 AE Enschede, The Netherlands

\begin{abstract}
Özetçe
Insan kolunun dinamik davranışının modellenmesi robotik, biyomedikal ve tıp alanlarinda önemli bir konudur. Bu çalışmada, iki serbestlik dereceli bir manipülatör kullanılarak, dışardan gelen kuvvet sarsımlarına maruz kalan kolun ardışık hareketi için bir tersine dinamik yöntemle bir model oluşturulması amaçlanmıştır. Sağlıklı katılımcılar ile gerçekleştirilen deneylerde, kolun sabit konum görevi ve düzlemsel hareket görevi esnasinda kol yüzeyinden ölçülen $E M G$ işaretleri ve kolun $x$ - ve $y$ - düzlemlerindeki yerdeğiştirmeleri kaydedilmiştir. Daha önceki çalışmamızda kola ait admitans, her iki görev için saylsal ve deneysel olarak kestirilmiştir. Deneysel yolla ve matris frekans cevabl fonksiyonu yönteminde kullanılan model parametreleri ile, tersine dinamik modelin parametreleri karşılaştırılacaktır.
\end{abstract}

\footnotetext{
Abstract

The modeling of the dynamic behavior of the human arm is an important issue in robotics, biomedical and medical fields. In this study, it was aimed to construct an inverse dynamics model for the sequential motion of the arm subjected to external force fluctuations using a two degree of freedom manipulator. In experiments with healthy participants, EMG signals measured from the arm surface during the arm's stationary position task and the planar motion task, and displacements in the $x$ - and $y$ plane of the arm were recorded. In previous studies, the arm admittance was estimated numerically and experimentally for both tasks. To demonstrate the dynamic arm dynamics, the model parameters obtained with the inverse model will be
}

compared with the parameters calculated experimentally and with matrix frequency response method's.

\section{Giriş}

İnsanlar günlük hayatta kol ve bacaklarını (uzanmak, tutmak, yürümek, koşmak, vs...) çok hızlı ve pratik bir şekilde kullanırlar. Bu kinetik hareketler öyle hızlı ve plansız bir şekilde gerçekleşir ki, çoğu zaman bunların oluşum mekanizması insanların aklından bile geçmez. İnsanlar maruz kaldıkları dış kuvvetlere karşı koymak için kaslarını kontrol edebilirler [1]. Günümüzde pek çok nörolojik ve ortopedik hastalıkların tanı koyma aşamasında, kas kuvvetlerinin bilinmesi önem taşımaktadır. Nöromüsküler sistemin çalışma mekanizmasının anlaşılması için gerçek zamanlı deneyler yapmak veya bu sistemlerin gerçeğe yakın modellerini sistem tanılama ile oluşturarak onlar üzerinde çalışmak gerekir [2]. Geçmiş yıllarda insan uzuvlarının kontrol mekanizmasının anlaşılması için pek çok deneysel çalışma yapılmıştır. Çalışmaların çoğunda el bileği, dirsek, omuz, ayak bileği ve diz gibi tek eklem ve az bir kısmında da çoklu eklemler çalışılmıştır [3-10]. Kas kuvvetlerinin canlılar üzerinden doğrudan ölçümü bazı durumlarda sınırlı kalmaktadır. Operatif yöntemler gerektirmekte veya araştırma laboratuvarlarında bazı ölçümler yapılabilmektedir. Elektromiyografi (EMG) hem uygulama kolaylığı açısından hem de insanların sinirsel yönelimlerini iyi bir şekilde ortaya koyması açısından tercih edilen bir yöntemdir. EMG ile eklem torklarını ortaya koymak mümkün olmaktadır fakat her bir kas kuvvetinin kestirilmesi pek mümkün değildir [ 3] .Kas kuvvetlerinin gerçeğe yakın 
değerleri ancak hem kas hem de iskelet sisteminin dâhil edildiği hesaplamalı modellerle ortaya koyulabilmektedir.

$\mathrm{Bu}$ çalışmada, kuvvet kontrollü dokunsal (haptik) bir manipülatör olan ARMANDA kullanılarak kol yüzeyinden farklı noktalardan ölçülen EMG işaretleri ile, dinamik kol hareketlerini veren model parametrelerinin tersine bir model ile hesaplanması amaçlanmıştır. Deneylerin gerçekleştirildiği bu dokunsal cihaz, insan koluna gerekli mekanik gücü sağlayarak, kişilere gerçek fiziksel nesneleri hareket ettirdiği hissini yaratmaktadır. Kişinin uyguladığ 1 kuvvet manipülatörün uç k1smında bulunan dönüştürücü (transduser) ile ölçülmekte ve manipülatörün tahrik kolu verilen referans yörüngeyi izlemektedir. Çalışmanın ilerleyen aşamalarında, daha önceki çalışmada [11] kullanılan model parametreleri ile tersine dinamik model parametrelerinin kıyaslanması hedeflenmiștir.

\section{Kas-İskelet dinamiği}

Dinamik insan hareketi kasların aktivasyonu ile oluşur ve buna bağlı olarak gerekli işleri yerine getirmek için eklemleri hareket ettirecek kuvveti üretir. İnsan kolunun kas dinamikleri bir kas modeli üzerine zaman bağımlı sınır şartları türetilerek geliştirilebilir[12].

Kas iskelet sisteminin matematiksel modeli matris formunda (1) deki gibi ifade edilir.

$M(q) \ddot{q}+C(q, \dot{q})+G(q)+R(q) F_{M T}+E=0$

$\mathrm{M}(\mathrm{q})$, sistem matrisi, $C(q, \dot{q})$ merkezkaç ve Coriolis ivmeleri, $\mathrm{G}(\mathrm{q})$ yerçekimi ivmesi, E diş kuvvetler ve $R(q) F_{M T}$ de kas eklemi torklarını ifade etmektedir.

Kas kuvvetlerinin kestirimi için literatürde ileri doğru çözüm yöntemleri, tersine çözüm yöntemleri ve EMG-uyarıml modeller uygulanmaktadır. İleri doğru dinamik çözüm yönteminde, sinirsel bir komutun ölçümü veya kestirimi ile işe başlanır ve daha sonrasında üç adımda eklem momentleri hesaplanır. Eklem momentlerine göre de hareket denklemleri elde edilir ve bu denklemler vasitasıyla uzuvlar hareket ettirilir. Üst düzey matematiksel bağıntılar içerdiğinden, doğrusal olmayan denklem çözümlerine ihtiyaç duyulabilir [13].

EMG-uyarımlı kas iskelet modellemesi, bir tür ileri doğru çalışan dinamik yaklaşımıdır. Bu yöntemde, deney yoluyla elde edilen EMG verileri, kişiye özgü geliştirilen bir kas iskelet modelinde girdi olarak kullanılır[14]. Kaydedilen EMG işaretleri, kas tendonlarının uyarımları ve ortaya çıkan kuvvet ve momentleri en güzel şekilde ortaya çıkarırlar. Bu yöntem literatürdeki optimizasyon tabanlı yöntemlere göre daha avantajlıdır çünkü kişilere özgü sinirsel mekanizma üzerindeki öngörüleri ortadan kaldırır [14]. EMG-uyarımlı yöntemde gerçek zamanlı bir kas iskelet modeline ihtiyaç duyulur.

Tersine dinamik çözümde ise, işe tersten başlanır yani ilk olarak uzuv üzerine gelen kuvvetler ve uzvun konumu ölçülür. Buna bağlı olarak uzvun hızı, eklem açıları, eklem torkları hesaplanır. Eklem tepki kuvvetleri ve momentlerine göre kas kuvvetleri de kestirilebilir.

Bu çalışmada tersine çözüm yöntemine göre kas parametreleri kestirilecektir. Deney düzleminde her biri $0.6 \mathrm{~m}$ uzunluğunda olan manipülatörün eklemleri, $\mathrm{x}$ - ve $\mathrm{y}$ - düzlemlerinde yatay olarak hareket ettirilmektedir. Tersine yöntemin zorluğu, kas kasılmalarının ve diğer tendonsal davranışların ortaya koyulmasında yaşanır. Eklem momentlerinin ve bileşke tepki kuvvetlerinin ifade edilmesi zordur. Ancak bu çalışmada, daha önce geliştirilmiş olan [2] kas-iskelet model parametreleri baz alınarak, bir doğrulama yapma imkanı bulunacaktır.

Deney düzeneğinin doğrusal olmayan insan kolu ile doğrusal çevreye ait ilişkisi Şekil 1'de sunulmuştur. Dış kuvvet $\mathrm{d}(\mathrm{t})$ ve tepki kuvveti olan $\mathrm{F}(\mathrm{t})$ sanal ortamda uygulanmaktadır. İnsan kolunun uyguladığ 1 tepki kuvvetinin yatay düzlemdeki ortogonal bileşenleri, manipülatör ile tutacak arasına yerleştirilen gerinimölçer ile ölçülmektedir. Optik açısal enkoderler ile de manipülatör eklem açıları ölçülerek, yer değiştirmeler hesaplanmaktadır. Sistem genel olarak mekanik hareket sistemi, hidrolik tahrik sistemi, kullanıcı için görüntüleme sistemi, işletim sistemi ve güvenlik sistemlerinden oluşmaktadır. [11].

Tepki kuvvetleri ve manipülatör eklem açıları $200 \mathrm{~Hz}$ lik örnekleme frekansı ile kaydedilmiştir.

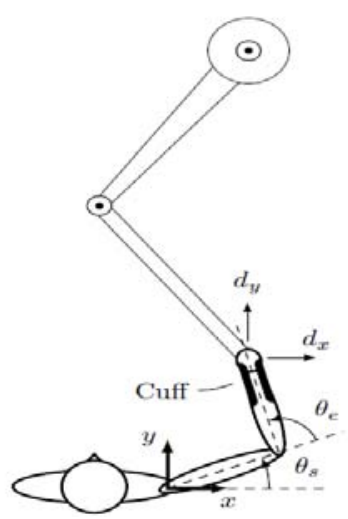

Şekil 1: Deney düzeneğinin şematik gösterimi. İki yönlü kuvvet sarsımları (dx ve dy).[15]

\subsubsection{Veri Toplama ve Analizi}

Deneylerde yaș ortalamaları 31.9 (5.1) olan on iki (8 erkek, 4 kadın) sağlıklı katılımcı yer almıştır. Çalışma bilimsel etik kurulu tarafından onaylanmış ve katılımcıların her biri gönüllü rıza formunu doldurmuşlardır.

Kol yüzeyinin temizlenip hazırlanmasının ardından, egemen kol üzerinden EMG ölçümlerinin yapılabilmesi için 8-kanallı bir EMG sistemine (DS-B04, Bagnoli-8, DelSys Inc., ABD) bağlı bulunan dört bipolar yüzey elektrodundan (DelSys Inc., ABD) veriler kaydedilir. Seçilen elektrotlar biceps (1), triceps (2), pectoralis majör (3) ve posterior deltoidstir (4) (Şekil 2) . EMG sinyalleri $2000 \mathrm{~Hz}$ 'de örneklenmiş, ve $5 \mathrm{~Hz}$ alçak geçiren filtre (Butterworth 4th-order) ile filtrelenmiştir. Daha sonra pencereleme ve normalizasyon adımlarından geçirilmiştir.

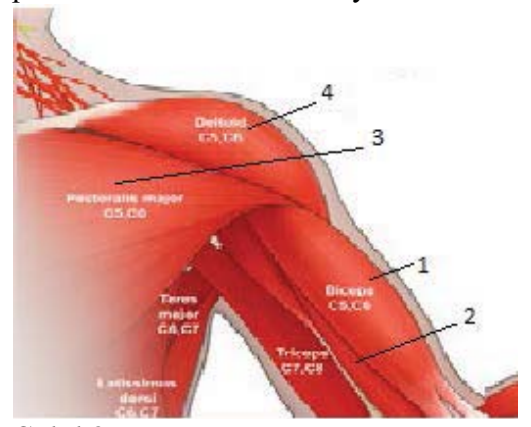

Şekil 2: EMG elektrot yerleşimi 


\subsubsection{Deney Tanımı}

Deneyler esnasında katılımcıların kolun ucundaki tutacağ 1 sıkı bir şekilde tutmaları ve görevleri uygun şekilde yerine getirmeleri istenmiştir (Şekil 3). Deneyler düzlemsel hareket ve sabit konum görevlerinden oluşmaktadır [11].

Düzlemsel Hareket Görevi (DHG): Kullanıcılardan, manipülatör kolundan sürekli titreşimler uygulanırken bu titreşimlere direnç göstermeleri ve bu esnada verilen hareket düzlemini takip etmeleri istenmiştir (P1 noktasından P2 noktasına en az sapma ile ulaşmak). P1 ve P2 noktaları kullanıcının karşısında yer alan bir ekranda sunulmaktadır (Şekil 4). Bu görev 32 saniyelik 20 tekrardan oluşmaktadır. Hareket hızının kullanıcılar arasında ortalama bir değerde olmasını sağlamak amacıyla metronom kullanılmıştır. Böylece kullanıcının belirli sürede bir çevrimi tamamlaması sağlanmıştır.

Sabit konum Görevi (SKG): Kullanıcılardan manipülatörü sabit bir konumda (P1 veya P2) tutmaları ve darbelerin neden olduğu konum sapmalarını karşılamaları istenmiştir. Her görev 32 saniyelik 12 tekrardan oluşmaktadır.

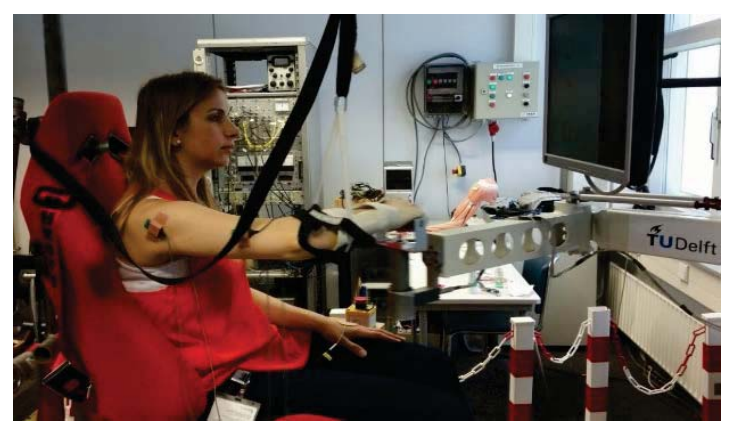

Şekil 3: Katılımc1 düzlemsel hareket görevi (DHG) gerçekleştirirken.

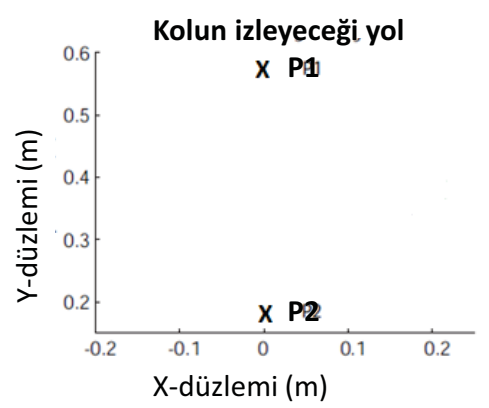

Şekil 4: Düzlemsel hareket görevi (DHG) için kolun izleyeceği yol.

\subsubsection{Bozucu işaret}

Doğrusal sistem tanılama için random gürültü, adım, darbe ve çoklu sinüs girişleri gibi tahrik sinyalleri kullanılmaktadır. Bu çalışmada kuvvet sarsımları için x- ve y- doğrultularında rastgele sürekli çoklu sinüs dalgaları uygulanmıştır (Şekil 5). Çoklu sinüs sinyali harmonik olarak değişen frekans ve fazlardaki bir dizi sinüs dalgası toplamından ibarettir [16]. Bozucu kuvvet 0.1 ile $40 \mathrm{~Hz}$ 'lik güç taşıyacak şekilde tasarlanmıştır.

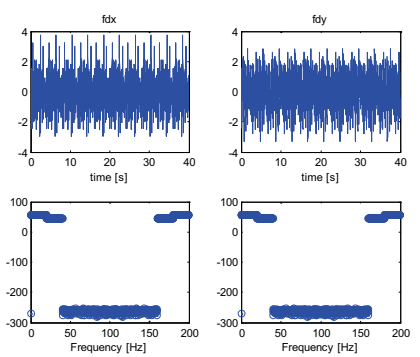

Şekil 5: x- ve y- doğrultularında uygulanan bozucu işaret

\subsection{Tersine Dinamik Model}

İnsan kol hareketinin matematik modeli, uygulanan kuvvet ve çıkıştaki konum arasındaki dinamik davranış olarak tanımlanır. Hareketin dinamiğini ifade eden denklemler ARMANDA'nın koordinatlarından hesaplandi. Kola uygulanan ve kolun karş1 koyduğu tepki kuvvetleri elde edildi. Şekil 6'daki kas iskelet dinamiği ve eklem kuvvet ve momentleri ilişsisinden kas kuvvetleri için tersine modeli oluşturacağız. Modelimizin sonuçlarını, deney esnasında kol yüzeyinden ölçtüğümüz değerlerle karşılaştıracağız.

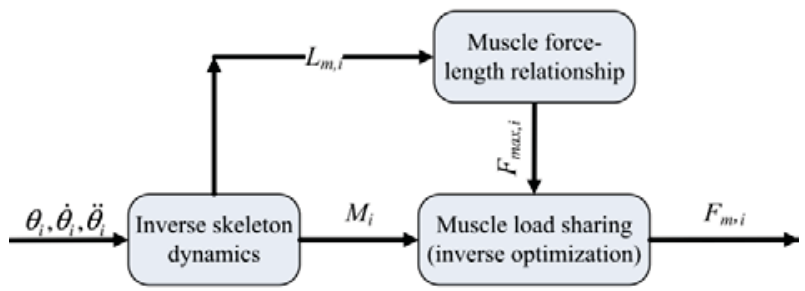

Şekil 6. Tersine modelin şematik gösterimi [2]

\subsection{Bulgular}

Aşağıda kolun düzlemsel hareket yapması (DHG) ve sabit konumda tutulması (SKG) anlarında, kol yüzeyinden kaydedilen ham EMG işaretleri ve bunların gürültüden arındırılıp, alçak geçiren filtreden süzüldükten sonraki halleri sunulmuştur (Şekil 7 ve Şekil 8).

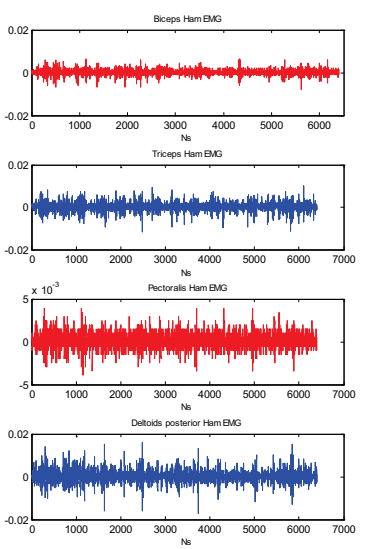

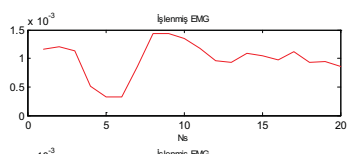
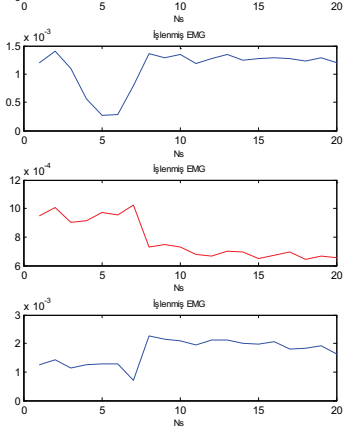
Şekil 7: DHG esnasında kaydedilen ham EMG sinyalleri (sol sütun) ve işlenmiş halleri (sağ sütun)
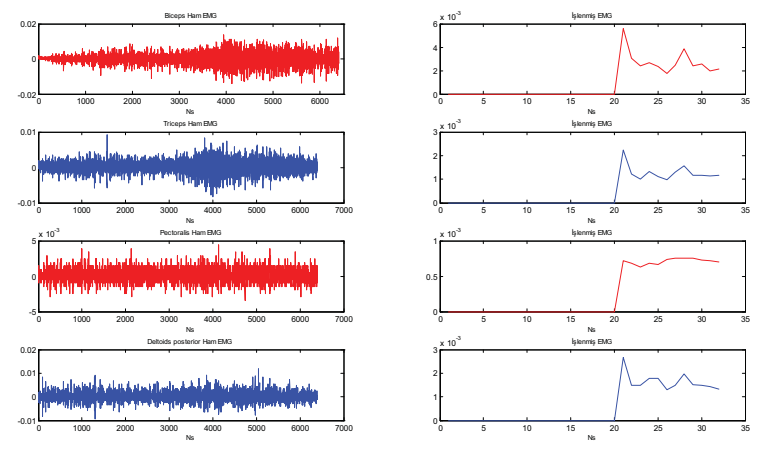

Şekil 8: SKG esnasında kaydedilen ham EMG sinyalleri (sol sütun) ve işlenmiş halleri (sağ sütun)

Süregelen çalıșma olduğundan, bu EMG verileri üzerinde analiz işlemleri devam etmektedir.

Şekil 9 da ise düzlemsel hareket esnasında kola uygulanan kuvvet ve buna bağlı olarak kolda oluşan sapmalar verilmiştir.
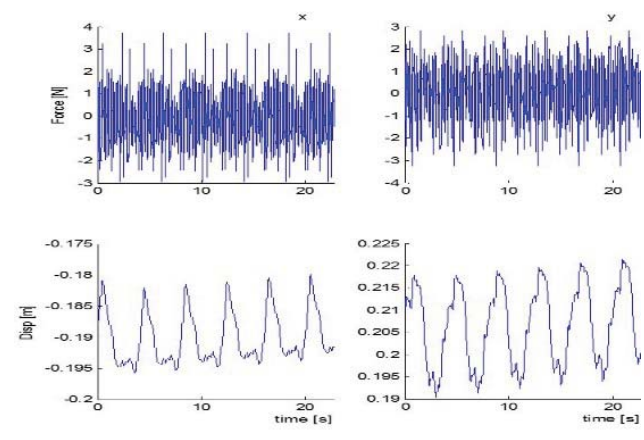

Şekil 9. DHG için x- ve y- düzlemlerinde uygulanan kuvvet, yer değiştirme ilişkisi.

\section{Sonuçlar}

$\mathrm{Bu}$ çalışmada insan kolunun düzlemsel ardışık hareketleri esnasındaki davranışının modellenmesi için, tersine dinamik EMG tabanlı bir yöntem kullanılarak kol parametrelerinin kestirilmesi amaçlanmaktadır. Kuvvet kontrollü manipülatör kullanılarak sabit konum görevi ve düzlemsel hareket görevleri gerçekleștirilmiștir. Bu esnada egemen kol yüzeyinden EMG işaretleri kaydedilmiştir. Ayrıca kolun x- ve y- düzlemlerindeki yer değiştirmeleri hesaplanmıştır. Sürekli kuvvet sarsımlarına maruz kalan kolun, minimum sapma ile görevleri yerine getirmesi esastır. Önerilen tersine dinamik EMG tabanlı yöntem ile elde edilecek kol parametreleri, kol yüzeyinden ölçülen sonuçlar ile karşılaştırılacaktır. Ayrıca bu parametreler daha önce matris frekans cevabı yöntemindeki kol parametreleri ile karşıllaştırılacaktır.

\section{Teșekkür}

Bu çalışmanın deneyleri TÜBİTAK-2219 "Yurt Dış1 Doktora Sonrası Araştırma Burs Programı" desteği kapsamında 2014-2015 y1lında Delft Teknoloji Üniversitesi Hollanda'da gerçekleştirilmiştir.

\section{Kaynaklar}

[1] E De Vlugt, FCT Van der Helm, AC Schouten. Closedloop multivariable system identification for the characterization of the dynamic arm compliance using continuous force disturbances: a model study. J Neurosci Methods 2003a; 122: 123-40.

[2] Nikooyan A.A., H.E.J. Veeger, P. Westerhoff, B. Bolsterlee,F. Graichen, G. Bergmann, F.C.T. van der Helm (2012). An EMG-driven musculoskeletal model of the shoulder, Human Movement Science, Vol. 31, 429-447.

[3] Zajac, F.E., Neptune, R.R., Kautz, S.A., 2003. Biomechanics and muscle coordination of human walking: Part II: Lessons from dynamical 230. simulations and clinical implications. Gait Posture 17, 1-17.

[4] H. Van der Kooij, R. Jacobs, B. Koopman, H. Grootenboer, A multisensory integration model of human stance control. Biol Cybern 1999; 80: 299-308.

[5] RF Kirsch, RE Kearney, JB. MacNeil Identification of time-varying dynamics of the human triceps surae stretch reflex. Exp Brain Res 1993; 97: 115-127

[6] EJ Perreault, RF Kirsch, PE Crago. Effects of voluntary force generation on the elastic components of endpoint stiffness. Exp Brain Res 2001; 141: 312-323.

[7] DT Westwick, RE Kearney, Identification of nonlinear physiological systems, IEEE Press, Canada, 2003.

[8] Fligge N., Urbanek H., van der Smagt P.,(2013).Relation between object properties and EMG during reaching to grasp, Journal of Electromyography and Kinesiology, Vol. 23, 402-410.

[9] Hosoda R.,Venture G., (2014), Human elbow joint torque estimation during dynamic movements with moment arm compensation method, Preprints of the 19th IFAC congress, 24-29 august, Cape twon, Africa.

[10] Dinant A. Kistemaker, Jeremy D. Wong, Paul L. Gribble The Central Nervous System Does Not Minimize Energy Cost in Arm Movements Journal of Neurophysiology. 2010; 104 ; 6, 2985-2994. DOI: 10.1152/jn.00483.2010

[11] NG Özmen, FCT.Van der Helm, AC Schouten, İnsan Kol Dinamiklerinin Farklı Koşullardaki Davranışının Kestirilmesi için Durum Çalışması, BIYYOMUT 2016, 35Kasim 2016, İzmir, Turkey

[12] R Happee ve FC van der Helm,1995 The control of shoulder muscles during goal directed movements, an inverse dynamic analysis. J Biomech.;28(10):1179-91.

[13] M Sartori, M Reggiani, D Farina, DG Lloyd (2012) EMGDriven Forward-Dynamic Estimation of Muscle Force and Joint Moment about Multiple Degrees of Freedom in the Human Lower Extremity. PLoS ONE 7(12): e52618. doi:10.1371/journal.pone.0052618

[14] T.S Buchanan,., D.G. Lloyd, K. Manal, ve T. F. Besier. Estimation of Muscle Forces and Joint Moments Using a Forward-Inverse Dynamics Model. Med. Sci. Sports Exerc., Vol. 37, No. 11, pp. 1911-1916, 2005

[15] E De Vlugt, FCT.Van der Helm Quantification of intrinsic and reflexive properties during multijoint arm posture. Journal of neuroscience Methods,2006, 155,328-349.

[16] J Schoukens, P Guillaume, R. Pintelon Design of broadband excitation signals. In: Godfrey K, editor. Perturbation Signals for System Identification. Englewood Cliffs, NJ: Prentice-Hall, 1993:126-59. 
